\title{
OS TRABALHADORES INVISÍVEIS: OS REFLEXOS DA CRISE NO DIREITO DO TRABALHO EM TEMPOS DE PANDEMIA
}

Paulo Roberto Fogarolli Filho. Mestrando em Direito da Sociedade da Informação no Centro Universitário das Faculdades Metropolitanas Unidas - FMU (São Paulo) ${ }^{1}$.

Resumo: Este artigo analisa a crise no Direito do Trabalho decorrente da ascensão tecnológica e da globalização, emergindo a figura dos trabalhadores invisíveis, trazendo como pano de fundo a pandemia do COVID-19. O artigo defende a busca por uma proteção legal para essa classe de trabalhadores, através da efetividade da Agenda 2030 (ONU, 2015) e da busca da implementação do Pacto Global do Emprego (OIT 2009), bem como pelo exercício da democracia concertada. A metodologia utilizada parte dos métodos dedutivo e indutivo, realizando a revisão da bibliografia, procurando visitar a doutrina, a jurisprudência e a legislação sobre o tema apresentado.

Palavras-chave: Sociedade da informação; Direito do trabalho; Crise; Pandemia; Trabalhadores invisíveis

\section{INVISIBLE WORKERS: THE REFLECTIONS OF THE CRISIS IN LABOR LAW IN TIMES OF PANDEMIC}

\begin{abstract}
This article analyzes the crisis in Labor Law originated by technological rise and globalization, emerging the figure of invisible workers, bringing the COVID-19 pandemic as a backdrop. The article defends the search for legal protection for this class of workers, through the effectiveness of the 2030 Agenda (UN, 2015) and the search for the implementation of the Global Employment Pact (ILO 2009), as well as the exercise of concerted democracy. The methodology used starts from the deductive and inductive methods, performing the bibliography review, seeking to visit the doctrine, jurisprudence and legislation on the topic presented.
\end{abstract}

Keywords: Information society; Labor law; Crisis; Pandemic; Invisible workers.

\section{1 - INTRODUÇÃO}

\footnotetext{
* Paulo Roberto Fogarolli Filho. Advogado. Mestrando em Direito da Sociedade da Informação no Centro Universitário das Faculdades Metropolitanas Unidas - FMU (São Paulo). Especialista em Direito do Trabalho e Processo do Trabalho da Pontifícia Universidade Católica de São Paulo, Brasil. paulofogarolli@duartegarcia.com.br Fone: +55 11 99996.7977. Rua Nebraska, 217, apartamento 112, Brooklin, São Paulo/SP, CEP 04560-011. CV: http://lattes.cnpq.br/8919039318088450 http://orcid.org/0000-0002-2860-9040
} 
A sociedade contemporânea está submersa na tecnologia e cada vez mais interconectada pelo uso intenso a internet. A ascensão tecnológica desencadeou o aparecimento e uma sociedade altamente conectada em ambiente virtual, de modo que as relações humanas passaram a ser desenvolvidas em velocidade também nessa nova ambiência digital.

Essa imersão tecnológica propiciou o surgimento de novas formas de trabalho, marcadas pela utilização de ferramentas digitais. As relações de trabalho passaram a se desenvolver nas plataformas digitais, emergindo novos fenômenos na sociedade atual, tais como a "uberização", os serviços de entrega por aplicativos disponibilizados nos smartphones, atraindo uma enorme quantidade de trabalhadores que assumiram o papel das máquinas, transmutando-se em verdadeiros motores (produtores de velocidade) para esse tipo de trabalho, não apenas pela atratividade do negócio, mas pela necessidade de buscar meios de subsistência, notadamente em períodos de crise econômica.

Os novos modelos de trabalho que surgiram na sociedade da informação acarretaram o aumento do poder do capital, na medida em que as novas tecnologias são controladas pelos empresários que possuem condições financeiras para gerir e organizar esse novo modelo de negócio virtual, fruto do processo da "glocalização planetária" (TRIVINHO, 2012, p. 15).

Esse novo empresariado transnacional que emerge do cenário atual marcado pelo avanço tecnológico não encontra mais as barreiras físicas que outrora impediam o crescimento do seu negócio, pois, agora, as empresas são formatadas para atuarem em ambiente virtual, de modo que surgem as grandes marcas globais, com presença em praticamente todos os países do globo, mesmo sem possuírem estabelecimentos físicos nestes locais.

O empoderamento do capital imprimiu enorme pressão sobre o trabalho, haja vista a enorme onda que começou a se formar na última década - e ainda em formação - sob a denominação de flexibilização da legislação trabalhista, minando os direitos da classe operária, transmutando-a em força motriz veloz, ou seja, em máquina (VIRILIO, 1996, p. 19).

Essa enorme onda - que ainda não se quebrou -, já trouxe impactos negativos para a legislação trabalhista, a exemplo da ampliação da terceirização das atividades da empresa e da denominada "Reforma Trabalhista", ou então, pelas Medidas Provisórias no $927^{2}$ e $936^{3}$

\footnotetext{
${ }^{2}$ D.O.U de 22/03/2020, pág. no 1 .

${ }^{3}$ D.O.U de 01/04/2020, pág. ${ }^{\circ} 1$.
} 
adotadas pelo Governo Federal no enfrentamento da pandemia originada pelo COVID-19, enfraquecendo ainda mais os trabalhadores, os quais encontram-se em posição de vulnerabilidade na sociedade hodierna.

E, nesse contexto, encontram-se os problemas a serem estudados. O estudo considera o cenário atual das relações de trabalho na sociedade da informação e a vulnerabilidade dos trabalhadores frente ao mercado de trabalho imerso na tecnologia, para então, identificar o empoderamento da classe empresária moderna que detém a tecnologia em seu favor, acarretando um novo abismo entre capital e trabalho; debruçando-se sobre o enfraquecimento da legislação trabalhista brasileira da última década, destacando-se as medidas adotadas para o enfrentamento da crise da pandemia do COVID-19.

Dessa forma, é possível identificar os reflexos dessas mudanças geradas pelo novo poder do empresariado aliado ao esvaziamento da legislação trabalhista, que propiciaram o surgimento dos denominados trabalhadores invisíveis.

O objetivo deste trabalho é analisar o surgimento dos trabalhadores invisíveis, imersos na crise econômica, fruto do esvaziamento da legislação do trabalho, e da crise pandêmica do COVID-19 e a necessidade de se buscar mecanismos legais de tutela desses trabalhadores frente ao novo empresariado fortalecido pelos aparatos e ferramentas digitais.

Para tanto, dividiu-se o presente trabalho em três capítulos. No primeiro capítulo analisaram-se as relações de trabalho na sociedade da informação, especialmente sobre a influência da tecnologia na sociedade atual, propiciando o fortalecimento da classe empresária. No segundo capítulo, examinou-se a crise no direito do trabalho pelo enfraquecimento da legislação trabalhista brasileira, abordando, inclusive, as medidas trabalhistas adotadas pelo Governo Federal brasileiro durante o período da pandemia. No terceiro capítulo, buscou-se discorrer sobre o surgimento dos trabalhadores invisíveis, debruçando-se sobre a necessidade de uma proteção legal para essa classe de trabalhadores.

A metodologia utilizada nesse trabalho parte dos métodos dedutivo e indutivo, realizando a revisão da bibliografia apontada nas referências, utilizando os referenciais teóricos de Bauman (1999) sobre os impactos da flexibilização no mercado de trabalho decorrente da globalização, o papel da velocidade na sociedade hodierna de Virilio (1996), bem como a conceituação do fenômeno "Glocal" abordado por Trivinho (2012), procurando visitar a doutrina e a legislação, bem como a pesquisa de jurisprudência sobre o tema apresentado. 


\section{2 - AS MUDANÇAS NAS RELAÇÕES DE TRABALHO ORIGINADAS PELA SOCIEDADE DA INFORMAÇÃO}

A velocidade da ascensão tecnológica aliada ao uso crescente da internet desencadeou profundas mudanças disruptivas nas relações humanas, reorganizando-se a estrutura social, elevando-se a sociedade a um novo patamar social, denominada como sociedade da informação.

Fuller e Soares (2018, p. 414) conceituam essa nova sociedade como aquela baseada em bens imateriais, cujo desenvolvimento está baseado em dados, informação e conhecimento, marcada pelo avanço tecnológico, ou seja, através da tecnologia, viabilizou-se o acesso à informação a um público cada vez maior, de forma ágil e quase que instantânea.

Essa nova e dinâmica organização social apresenta duas características marcantes, sendo a primeira pela velocidade da criação, transmissão e circulação do conhecimento, informações, ideias e doutrinas, e a segunda pela valorização econômica dos bens imateriais ligados ao conhecimento em níveis superiores aos bens materiais (MARTINS, 2020, p.161).

Barreto Junior e Naspolini (2019, p.139) apontam que a principal característica da sociedade da informação é a "viabilidade tecnológica do acesso a informações advindas de qualquer lugar do mundo em tempo quase real, de forma inédita na história pretérita, de modo que a informação é o centro gravitacional desta nova era".

Essa sociedade hodierna "infotecnológica” (TRIVINHO, 2017, p.17) ultra veloz sofreu os impactos do estilhaço das barreiras físicas planetárias, originando uma sociedade altamente interligada, fruto de um processo de "reestruturação mundial", construído pela tríade "integração", "globalização" e territorialização", emergindo uma nova hierarquia sociocultural em escala planetária (BAUMAN, 1999, p. 78).

Dessa maneira, a sociedade atual está em um patamar novo, regida pela velocidade, tecnologia e pelo uso maciço da internet, de modo que as relações humanas se desenvolvem nos meios digitais, ou no "cyberspace” (TRIVINHO, 2012, p.74). Existe, portanto, uma virtualização das relações sociais, conforme identifica Sodré (2002, p. 16):

Está depois em jogo um novo tipo de formalização da vida social, que implica uma outra dimensão da realidade, portanto formas novas de perceber, de pensar e contabilizar o real. Impulsionadas pela microeletrônica e pela computação ou informática, as neotecnologias da informação introduzem os elementos do tempo real (comunicação instantânea simultânea e global) e do espaço virtual (criação por computador de ambientes artificiais e interativos), tornando 'compossíveis' outros mundos, outros regimes de visualidade pública. 
Teixeira (2015, p. 17) aponta que a sociedade atual se tornou totalmente dependente da internet, de modo que essa situação de dependência vem produzindo uma inversão peculiar em nossa relação com a tecnologia, na medida em que "ela já não é mais adaptada a nós, seres humanos; ao contrário, estamos cada vez mais nos adaptando a ela, pois as máquinas não são mais nossa extensão, nós é que nos tornamos extensões delas”.

Constitui-se pauta do dia dos operadores do direito os impactos da indústria $4.0^{4}$ na modernidade, cujo origem foi proveniente da quarta revolução industrial e se caracteriza por um conjunto de tecnologias que permite a fusão do mundo físico, digital e biológico.

Essa revolução digital, desabrochada por uma gama de inovações e ferramentas tecnológicas, não apenas alterou a organização social e as formas de produção e de consumo da sociedade, mas, também, desafiou o universo do trabalho.

Moreira (2020, p. 03) identifica uma evolução do trabalho, de modo que atualmente pode-se dizer que estamos na era do Trabalho 4.0:

\begin{abstract}
A evolução começou com o trabalho 1.0., do século XIX e da revolução industrial associado ao surgimento da sociedade industrial, o que originou mudanças no modo de produção e na própria organização do trabalho. Depois temos o trabalho 2.0., do século XX, com o surgimento da produção em massa e advento do Estado Social. Há, depois, o trabalho 3.0, a partir da década de 70 do século passado, com a globalização e o surgimento do trabalho no computador e a informática; por último tem-se o trabalho 4.0, relacionado com a digitalização, o trabalho em plataformas, a economia colaborativa, o trabalho integrado, que origina uma mudança de valores e de novos compromissos sociais. Este tipo de trabalho será mais digital, flexível e interconectado.
\end{abstract}

Rodrigues (2018, p. 04) aponta que esse movimento da sociedade atual revela o nascimento da denominada "economia colaborativa", na qual se compartilha e troca produtos e serviços através de plataformas digitais, de modo que as barreiras de desconfiança foram reduzidas, tomando como base a utilização de perfis de usuários com avaliações e referências, que dão origem a novas formas de se relacionar, compartilhar e rentabilizar bens econômicos em modelos de negócios tradicionais.

Nesse contexto, esses aparatos digitais propiciaram o surgimento de uma nova classe empresarial, que é aquela que não mais precisa de um local físico para operar seu negócio,

\footnotetext{
${ }^{4}$ A quarta revolução industrial, que terá um impacto mais profundo e exponencial, se caracteriza, por um conjunto de tecnologias que permitem a fusão do mundo físico, digital e biológico.
} 
pois agora o que essa nova classe precisa é de informação e de um espaço virtual para o desenvolvimento de suas atividades empresariais.

Os exemplos são fartos nessa nova ambiência, como, por exemplo, o Uber que se tornou a maior empresa de mobilidade urbana no mundo, mas não possui carros ou motoristas como seus empregados, ou então, a empresa global do segmento imobiliário denominada Airbnb que não possui hotéis de sua propriedade, ou, ainda, os aplicativos Ifood e Rappi que se tornaram os maiores do segmento de delivery no Brasil sem possuir motocicletas de sua titularidade ou entregadores como seus empregados (ANTUNES, 2018, p. 35.).

As empresas que atuam no segmento de varejo também deixaram de atuar em estabelecimentos físicos e migraram para o ambiente virtual, a exemplo das duas empresas atuantes no Brasil: Magazine Luiza e Americanas.

Conforme noticiado na mídia no mês de junho/2020, mesmo no pior cenário econômico mundial desencadeado pela pandemia do novo coronavírus (COVID19), as companhias que atuam no e-commerce ${ }^{5}$ registraram a maior alta na Bolsa de Valores Mobiliários, justamente pelo fato de que o ambiente virtual não encontra os limites e barreiras no ambiente físico que outrora regia o desenvolvimento das relações sociais.

Essa nova classe empresária surge ainda mais forte, pois além de possuir o poder tecnológico, ela consegue se desenvolver sem a necessidade de contar com empregados próprios. O abismo entre capital e trabalho fica ainda mais evidente e maior na sociedade da informação, criando uma "invisibilidade legal do trabalho", ou então, como citado por Cuesta (2017, p. 107) é o "efeito imediato é uma invisibilidade legal do trabalho pelo relato de outra pessoa a partir da aparente inexistência do sujeito do negócio."6.

Rodrigues (2019, p. 15) aponta que na sociedade atual existem novas formas de superexploração da força de trabalho, uma vez que os serviços que foram privatizados fizeram florescer novos mecanismos utilizados pelo capital, que atuam nas tecnologias de informação e comunicação (TIC), call center, telemarketing, hotelaria, limpeza, comércio, fast-food, que frequentemente realizam trabalhos intermitentes, temporários, informais, autônomos, desregulamentados, à margem da legislação social protetora do trabalho.

\footnotetext{
${ }^{5}$ Esta nova tecnologia inovou as transações de bens, serviços e informações realizadas entre empresas e indivíduos em ambiente eletrônico. Teve início nos Estados Unidos, em meados da década de 1990, sendo rapidamente propagado para a Europa e demais localidades do mundo. (MENDES, 2013, p. 09)

6 Texto original: "efecto inmediato una invisibilidad jurídica del trabajo por cuenta ajena a partir de la aparente inexistencia del sujeto empresarial.".
} 
Afora isso, a ascensão tecnológica fez surgir novas formas de trabalho, como abordado por Franco e Ferraz (2019, p. 848) que apontam o surgimento do trabalho denominado crowdwork, ou seja, o trabalho da multidão que se torna integrado ao sistema produtivo. Um exemplo de crowdwork é o da empresa Amazon, que lançou o segmento Mechanical Turk, em 2005, que é uma plataforma virtual que auxilia as empresas a encontrar pessoas para executar tarefas on-line, as quais os computadores executam de modo insatisfatório ou incompleto (Moreira, 2020, p. 08).

A "uberização" que foi ampliada por força da dificuldade de uma massa de trabalhadores encontrar vaga de trabalho aliada aos patamares assustadores do número de desempregados ao redor do mundo, criando uma pulverização dessa modalidade de trabalho na sociedade atual, ou então, conforme identificado por Gaia (2018, p. 14), “os elevados índices de desemprego provocam nesse contexto social a incessante busca de realocação do trabalhador no mercado de trabalho, como forma de garantir a própria sobrevivência, o que acarreta o aumento da informalidade e de outras formas de precarização do trabalho.".

Nesta nova organização social existe uma marca típica das relações de trabalho, qual seja: centrada na informalidade, desenvolvida sem a guarida de legislação protetiva desses trabalhadores, cujo reflexo decorre na nuvem cinzenta que permeia o Direito do Trabalho denominada como "flexibilização" das relações laborais. Bauman (1999, p. 112) identifica esse processo de "flexibilização" da seguinte forma:

\footnotetext{
O mercado de trabalho é rígido demais; precisa tornar-se flexível, quer dizer, mais dócil e maleável, fácil de moldar, cortar e enrolar, sem oferecer resistência ao que quer que se faça com ele. Em outras palavras, o trabalho "flexível" na medida em que se torna uma espécie de variável econômica que os investidores podem desconsiderar, certos de que serão as suas ações e somente elas que determinarão a conduta da mão-de-obra.
}

Esse cenário atual expõe a vulnerabilidade do trabalhador, tendo em vista que a inteligência artificial acarretou não apenas a redução de postos de trabalho, mas revelou que a atual legislação trabalhista não oferece condições mínimas de proteção para os trabalhadores, situação ainda mais agravada pela crise global vivida por força da pandemia do COVID-19.

Assim, o Direito do Trabalho é exposto a um novo ambiente marcado por relações agora realizadas em ambiente virtual, de maneira que surgem temas como inteligência artificial, algoritmos, uso da internet, em especial pelos aparatos digitais disponíveis aos empresários que podem acarretar não apenas violação aos direitos fundamentais da pessoa humana, mas, também, o desaparecimento de postos de trabalho. 


\section{3 - A CRISE NO DIREITO DO TRABALHO: DO FENÔMENO "GLOCAL" AO ENFRAQUECIMENTO DA LEGISLAÇÃO TRABALHISTA EM TEMPOS DE PANDEMIA}

As relações do trabalho foram alvo de imensa transformação estimulada não apenas pelo avanço tecnológico, mas também pelos efeitos da globalização aliados ao processo denominado de flexibilização da legislação do trabalho instaurado pela força do capital que propagava que a dita flexibilização seria capaz de trazer o aumento do emprego e o fomento econômico.

Todavia, essa busca frenética dos empresários em torno da flexibilização da legislação trabalhista ocasionou efeitos nefastos para o Direito do Trabalho, especialmente pela enorme redução dos direitos dos trabalhadores, de modo que atualmente fala-se em crise no Direito do Trabalho (PÔRTO, 2016, p. 110).

O primeiro ponto para compreender a crise vivida no Direito do Trabalho decorre da compreensão do fenômeno da globalização.

Beck (1999, p. 16) parte da conceituação de globalização como significação de "processos", em cujo andamento os Estados nacionais veem a sua soberania, sua identidade, suas redes de comunicação, suas chances de poder e suas orientações sofrerem a interferência cruzada de atores transnacionais.

Nesse cenário de interligação do mundo foi plantada a falsa ideia de que existe uma tendência de melhora e fomento da economia de todos os países, eis que vendeu-se a ideia de que a economia estaria interligada, de modo que os países poderiam realizar negócios com mais frequência, ocorrendo uma redistribuição do emprego, o que antes não ocorria no cenário mundial antes da explosão da globalização (PÔRTO, 2016, p.115).

Isso, de fato, não ocorreu. Conforme retratado por Beck (2006, p. 117), já não se trata mais da redistribuição do emprego, mas da redistribuição do desemprego, pois "enquanto crescem as margens de lucro das empresas de atuação global, estas privam o caro Estado de postos de trabalho e do pagamento de impostos e deixam para ele os custos do desemprego e do avanço civilizatório".

Soares $(2019$, p.289) destaca que o capital passou a buscar novas regiões para produzir em áreas de baixos salários e se valorizar financeiramente em paraísos fiscais. Esse "processo de flexibilização da produção e acumulação permite ao capitalista exercer uma 
maior pressão sobre a vida dos trabalhadores, estes que já veem suas lutas enfraquecidas com o esvaziamento sindical e a redução cada vez maior de direitos vislumbrados nesta era neoliberal".

Trivinho (2012, p.47) acrescenta a esse fenômeno o termo "glocal", expressão utilizada para "responder a uma situação histórica cada vez mais globalizada e interdependente política, econômica e culturalmente e com repercussões continuadas no domínio dos negócios, na qual uma empresa vê-se compelida a fazer uso de seu capital disponível de flexibilidade adaptativa a culturas locais".

Naspolini e Ferreira (2020, p. 06) reforçam esse entendimento e destacam:

\begin{abstract}
As empresas transnacionais investem em novas tecnologias e no uso de inteligência artificial, e transferem seus processos fabris para "países pobres", que oferecem mão de obra barata e instalações ávidas por atender às novas demandas. Isto somado às facilidades da tecnologia da informação gera aumento da produtividade e do comércio e, por consequência, dos lucros, aumentando a concentração de renda nessas grandes corporações e fazendo com que os limites do que é aceitável sejam deslocados em função dos resultados, numa visão maquiavélica de que os fins podem preponderar sobre os meios.
\end{abstract}

O exemplo desse cenário da globalização na taxa do desemprego pode ser destacado no Brasil. De acordo com os dados estatísticos disponibilizados pelo IBGE em 2010, a taxa de desocupação (desempregados) no Brasil era de $6 \%$ da população, ou seja, 1,4 milhões de brasileiros não tinham empregos. Em comparação, em abril de 2020, o número da taxa de desocupação atingiu o patamar histórico de 12,6\%, atingindo 12,8 milhões de desempregados.

Ora, se a globalização aliada ao avanço tecnológico foi vendida como fonte geradora de empregos e de fomento da economia, esse número de taxa de desocupação deveria ter caído vertiginosamente no Brasil, o que, de fato, não ocorreu.

Afora isso, a crise econômica também foi um fator essencial para a ruptura dos direitos trabalhistas. Viegas $(2016$, p. 02) relata que a crise econômica revela uma oportunidade perfeita para pressionar pela flexibilidade do Direito Trabalhista, sob a justificativa de redução do custo de produção, pois "aqueles que defendem a flexibilização sustentam que esta medida democratiza as relações entre empregado e empregador, quando confere as eles o direito de negociarem as condições laborais e, consequentemente, reduz os riscos de eventuais demissões nos períodos de recessão".

Surge, então, a figura da flexibilização trabalhista que pode ser compreendida como o conjunto de medidas destinadas a atenuar, adaptar ou eliminar direitos trabalhistas ante a 
suposta imperatividade das normas jurídicas em contraponto à realidade econômica vigente (TEIXEIRAS; BARCELOS, 2018, p. 04).

A ampliação da terceirização no Brasil foi um dos pontos da denominada flexibilização dos direitos trabalhistas. Relembre-se que o Tribunal Superior do Trabalho fixou entendimento majoritário e pacífico, após anos de debates em processos envolvendo terceirização das atividades empresariais, no sentido de que a terceirização de atividade-fim (aquelas essenciais) da empresa não poderia ocorrer, sendo permitida apenas a terceirização de atividade-meio, conforme item III da Súmula 331 abaixo reproduzida:

\footnotetext{
Súmula no 331 do TST

CONTRATO DE PRESTAÇÃO DE SERVIÇOS. LEGALIDADE (nova redação do item IV e inseridos os itens V e VI à redação) - Res. 174/2011, DEJT divulgado em 27,30 e 31.05.2011.

III - Não forma vínculo de emprego com o tomador a contratação de serviços de vigilância (Lei $n^{\circ} 7.102$, de 20.06.1983) e de conservação e limpeza, bem como a de serviços especializados ligados à atividade-meio do tomador, desde que inexistente a pessoalidade e a subordinação direta.
}

Todavia, a Lei n 13.429 de 31 de março de 2017, a chamada "Lei da Terceirização", ampliou a possibilidade de terceirização em todas as atividades empresariais, abrindo-se uma enorme fenda para a precarização das relações de trabalho.

Oportuno rememorar a exposição de motivos do Projeto de Lei no 4.302 de 1998, que emanou do Poder Executivo, que deu origem à citada Lei da Terceirização retro indicada, especialmente o item “17”, pois o Ministro do Trabalho da época Paulo Paiva entendeu que a ampliação da terceirização seria importante pelo seguinte motivo:

17. Com as mudanças propostas, pretende-se facilitar e desburocratizar a contratação do trabalho, sem prescindir dos direitos básicos garantidos aos trabalhadores, gerando-se, dessa forma, a abertura de novos postos de trabalho.

Infere-se, portanto, que a Lei da Terceirização também foi divulgada sob o fundamento de "abertura de novos postos de trabalho". Entretanto, os dados divulgados pelo IBGE sobre a taxa de desocupação (desempregados) no Brasil em 2017 foi 12,3 milhões de brasileiros. Em comparação, em abril de 2020 (três anos de vigência da referida Lei da Terceirização), o número da taxa de desocupação atingiu o patamar histórico de 12,8 milhões de desempregados. Dessa maneira, pode-se concluir que não houve abertura de novos postos de trabalho.

Lara e Silva (2019, p. 491) alertam que a ampliação da terceirização está associada à busca de redução de custos com a força de trabalho, o que corresponde à lógica empresarial 
de que, em momentos de baixas taxas de crescimento econômico e condição desfavorável de competição em relação ao exterior, a saída é reduzir ao mínimo o custo da força de trabalho.

Nessa toada de flexibilização e ofensiva contra o Direito do Trabalho, a Lei 13.467 de 13 de julho de 2017, denominada como "Lei de Reforma Trabalhista" invadiu o ordenamento jurídico brasileiro para reduzir ainda mais os direitos dos trabalhadores.

A Lei de Reforma Trabalhista trouxe uma série de mudanças para o Direito do Trabalho, contudo, o objeto do presente estudo não é esgotar as alterações oriundas dessa nova Lei, mas destacar os principais pontos que propiciaram afronta aos direitos dos trabalhadores.

O esvaziamento do poder sindical foi uma das mudanças mais sensíveis da Lei de Reforma Trabalhista, pois a contribuição sindical deixou de ser obrigatória e passou a ser facultativa, de modo que grande parte dos Sindicatos fecharam as portas pelo impacto financeiro imediato da nova lei. Ademais, a homologação da rescisão do contrato de trabalho dos empregados com mais de doze meses de emprego deixou de ser submetida ao sindicato, podendo ser feita diretamente pelo empregador, pois o parágrafo $1^{\circ}$ do artigo 477 da CLT, que garantia a participação e assistência dos sindicatos na rescisão contratual, foi revogado pela Lei de Reforma Trabalhista.

Os trabalhadores além de estarem desassistidos pelos sindicatos, também terão dificuldades de se socorrerem ao Poder Judiciário, considerando que a Lei de Reforma Trabalhista determinou a fixação de honorários de sucumbência nos processos do trabalho, isto é, o empregado terá que pagar honorários para o advogado da empresa, caso seus pedidos não sejam acolhidos pela Justiça do Trabalho, conforme expressa disposição do artigo 791-A da CLT $^{7}$.

Além disso, os empregados também terão que suportar o pagamento das custas processuais da ação trabalhista, caso não sejam beneficiários da Justiça Gratuita, ou então, não compareçam na audiência inaugural.

Assim, o direito de acesso à Justiça previsto no artigo $5^{\circ}$, inciso $\mathrm{XXXV}$, da Constituição Federal de 1988 foi praticamente tolhido dos trabalhadores, pois muitas ações deixaram de ser propostas pelo receio dos trabalhadores de terem que pagar os honorários do

\footnotetext{
${ }^{7}$ Art. 791-A. Ao advogado, ainda que atue em causa própria, serão devidos honorários de sucumbência, fixados entre o mínimo de 5\% (cinco por cento) e o máximo de 15\% (quinze por cento) sobre o valor que resultar da liquidação da sentença, do proveito econômico obtido ou, não sendo possível mensurá-lo, sobre o valor atualizado da causa.
} 
advogado da parte contrária, além do pagamento das custas processuais, tornando excessivamente onerosa a ação trabalhista.

O Tribunal Superior do Trabalho realizou um levantamento estatístico da diminuição do número de novas ações trabalhistas propostas após a vigência da Lei de Reforma Trabalhista e constatou que no primeiro ano de vigência da nova lei houve uma queda de 36\%, na medida em que em 2017 foram distribuídos 2.013.241 (dois milhões, treze mil, duzentos e quarenta e um) novos processos, contudo, em 2018 foram distribuídos 1.287.208 (um milhão, duzentos e oitenta e sete mil, duzentos e oito) novos processos.

Além dos exemplos citados, pode-se indicar, ainda, a fixação e limitação da indenização por danos morais (a indenização terá um teto máximo de valor monetário); as denominadas horas in itinere (tempo do deslocamento do trabalhador da sua residência até o local de trabalho e vice-versa) que deixam de ser computadas como tempo à disposição do empregador; possibilidade de adoção de banco de horas diretamente com o empregador, dispensando-se a participação do sindicato; a criação da figura da quitação anual de débitos trabalhistas, pois o empregador poderá exigir do empregado a outorga de quitação anual de todos os débitos trabalhistas.

Silveira e Meireles (2019, p. 06) destacam que a Lei de Reforma Trabalhista "embora tenha sido trazida com o argumento da modernização das relações trabalhista, em verdade, precarizará ainda mais essas relações".

Nesse contexto de mudanças disruptivas, na segunda década do século XXI a sociedade foi colocada diante de seu maior desafio: o enfrentamento da pandemia desencadeada pelo COVID-19. A Organização Mundial da Saúde (OMS) declarou, em 30 de janeiro de 2020, que o surto da doença causada pelo COVID-19 constitui uma Emergência de Saúde Pública de Importância Internacional, isto é, o mais alto nível de alerta da Organização, conforme Regulamento Sanitário Internacional. Em 11 de março de 2020, a COVID-19 foi caracterizada pela OMS como uma pandemia.

A pandemia desencadeou uma profunda crise global, considerando que a doença gerada pelo COVID19 não pode ser combatida ou remediada por uma vacina, tampouco tratada com um medicamento capaz de frear a doença, de modo que os cidadãos foram instados a ficarem reclusos em suas residências, a fim de não propagarem a doença e evitarem a exposição ao vírus. Esse cenário caótico de isolamento social impactou diretamente na atividade econômica, levando ao fechamento de empresas e aumento do desemprego, 
forçando o Governo brasileiro a adotar uma série de medidas econômicas, sob o argumento de que os empregos seriam preservados.

Assim, o Direito do Trabalho foi minado pela fatídica Medida Provisória $n^{\circ} 936$ de 01 de abril de $2020^{8}$ editada pelo Presidente da República Federativa do Brasil que concedeu carta branca aos empresários para reduzirem em até $70 \%$ o salário dos trabalhadores, sob a pecha de garantir a continuidade dos empregos, e implementou o benefício "Programa Emergencial de Emprego e Renda”, no qual o Estado iria suportar parte do pagamento desse salário reduzido durante o período de pandemia. Entretanto, o que se viu, foi um enorme prejuízo financeiro aos trabalhadores que ainda possuíam um posto de trabalho ocupado, pois esse benefício implementado pelo Estado teve uma limitação de pagamento com base no percentual do valor mensal do seguro-desemprego, cujo teto vigente em 2020 perfaz a quantia de $\mathrm{R} \$ 1.813,03$ (mil, oitocentos e treze reais e três centavos).

Ademais, o Governo Federal brasileiro também editou a Medida Provisória no $927^{9}$ que estabeleceu uma série de flexibilizações nas relações do trabalho, a exemplo da antecipação de férias, teletrabalho, banco de horas, antecipação de feriados, diferimento do recolhimento do FGTS, dentre outras medidas.

Esse cenário de enfraquecimento da legislação do trabalho serviu para o aprofundamento da informalidade da classe trabalhadora, pois, agora, além da substituição dos trabalhadores por máquinas cada vez mais presente na sociedade hodierna, o empresário sequer precisa contar com mão de obra própria, podendo terceirizar todas as suas atividades, de modo que os trabalhadores ainda resistentes no mercado de trabalho estão ainda mais vulneráveis pelo esvaziamento da legislação protetora de seus direitos.

Revela-se, portanto, a crise no Direito do Trabalho, pois essas mudanças legislativas não desencadearam o aumento dos postos de trabalho, pelo contrário, revelaram elevada precarização e a superexposição dos trabalhadores ao capital, assim, o Direito do Trabalho encontra-se em xeque, sem conseguir amparar os trabalhadores vulneráveis com a devida proteção legal.

\section{4 - OS TRABALHADORES INVISÍVEIS}

\footnotetext{
${ }^{8}$ D.O.U., publicado em 01/04/2020, Edição: 63-D, Seção: 1 - Extra, Página: 1.

${ }^{9}$ D.O.U., publicado em 22/03/2020, Edição:55-L Seção: 1 - Extra, Página: 1.
} 
Essa luta desigual entre capital e trabalho travada na sociedade da informação revelou uma nova categoria de trabalhadores, os denominados trabalhadores invisíveis, cuja marca característica é a ausência visibilidade social, permanecendo escondidos da sociedade. Todavia, decorre daí a problemática do tema: o que é ser ou estar visível na sociedade atual.

Sob o aspecto físico, visível é o que visto em nosso campo de visão, isto é, o que enxergamos através dos nossos olhos. Por sua vez, o invisível é aquilo que está escondido, oculto, que não conseguimos perceber pelo nosso campo de visão, ou então, aquilo que está longe da luz, imerso na escuridão.

No fluxo normal de nossas vidas diárias, a visibilidade está relacionada com as potencialidades físicas do nosso sentido da visão e com as características espaciais e temporais da circunstância em que nos encontramos: não podemos ver a partir de uma certa distância, não vemos na ausência de uma certa quantidade de luz e não podemos ver o futuro ou o passado. O que vemos é aquilo que está dentro de nosso campo de visão, sendo que os limites deste campo são dados pelas características espaciais e temporais do aqui e do agora (THOMPSON, 2008, p. 20).

Todavia, a visibilidade social objeto do presente estudo não se relaciona, exclusivamente, com o aspecto físico da visão, mas com o fato de ser reconhecido pelo outro na sociedade, tornando-se presente na sociedade.

Costa (2008, p. 15) sustenta que a origem desse do fenômeno da invisibilidade pública está na "reificação" e destaca "somente humanos já reduzidos e tidos como objetos podem parecer impotentes na capacidade de se fazerem interpelar como humanos e de interpelarem outros humanos como iguais".

Essa incapacidade tratada por Costa pode ser identificada pelo fato de os trabalhadores serem colocados à margem da sociedade, por atuarem em atividades rotuladas como "simples", sem pouca importância para o desenvolvimento da sociedade, de modo que os trabalhadores não possuem força para se colocarem e reivindicarem os seus direitos.

Castells (2019, p. 558) aborda essa questão na sociedade da informação, pois a "mão de obra está desagregada em seu desempenho, fragmentada em sua organização, diversificada em sua existência, dividida em sua ação coletiva".

Borges e Silva (2018, p. 05) exemplificam esse tema pela função de gari, na medida em que essa atividade é pouco reconhecida no ambiente coletivo, sendo possível apontar que os garis vivem nessa invisibilidade social. Apontam, ainda, que seria "uma forma manifestada 
de preconceito que migra da sociedade para o ambiente da família, cristalizando-se em traumas profundas em relação a autoestima e aceitação”.

Com efeito, a sociedade da informação revela a existência de uma enorme massa de trabalhadores que não são reconhecidos na sociedade, justamente por esse olhar preconceituoso enraizado na modernidade, no sentido de que apenas as profissões com formação superior são aquelas que colocam o indivíduo na vitrina social do que é bom e admirável, colocando esses trabalhadores escondidos sob o véu da escuridão do preconceito social.

Os trabalhadores dos aplicativos de delivery, tais como Ifood, Rappi, Uber Eats, são o exemplo de trabalhadores invisíveis na sociedade moderna. Relembre-se que esses aplicativos servem como elo entre os entregadores e os terceiros (em regra, restaurantes que dependem da entrega de suas refeições e são cadastrados nos aplicativos).

Esses trabalhadores atuam por longas horas, com jornada de trabalho extenuantes, recebendo sua remuneração com base na quantidade de entregas realizadas, utilizando motocicletas ou bicicletas, sem qualquer inspeção ou manutenção, podendo sofrer acidentes durante o percurso de entrega, sem contar com qualquer respaldo do aplicativo ou mesmo dos terceiros. Destaca-se, ainda, que, na maioria dos casos, esses trabalhadores sequer possuem condições de realizar as suas necessidades fisiológicas básicas, pois eles atuam sem o fornecimento de instalações disponíveis para a higiene mínima básica (GAIA, 2018, p. 239).

Acrescente-se que esses trabalhadores não gozam de qualquer proteção legal, uma vez que passaram a atuar na informalidade, sob o manto do dito "trabalho autônomo", apenas realizando o seu cadastro nas plataformas disponibilizadas pelos referidos aplicativos, sem qualquer vínculo jurídico, diferentemente do que ocorre com os garis que, em regra, atuam com a proteção legal da Consolidação das Leis do Trabalho, já que contam com a anotação do vínculo na carteira de trabalho.

Essa migração do trabalho regido pela formalidade para a informalidade das plataformas digitais é resultado da dificuldade de recolocação do mercado de trabalho, pois esses trabalhadores encontram essa forma de trabalho para ter o mínimo de subsistência. Entretanto, o Ministério Público do Trabalho da Procuradoria Regional do Estado de São Paulo revela a preocupação dessa migração e destaca o "canto da sereia", conforme destacado na sua Réplica apresentada na Ação Civil Pública (processo autuado sob o número 1000100- 
78.2019.5.02.0037 em trâmite perante a $37^{a}$ Vara do Trabalho de São Paulo/SP) movida contra o Ifood:

\begin{abstract}
I - O CANTO DA SEREIA
16. Os aplicativos de entregas rápidas são o novo canto das sereias nas relações de trabalho. Prometem uma panaceia, um mundo encantado e idílico em que todos ganham, assegurando aos trabalhadores uma vida melhor, livres das amarras da dependência do emprego formal. Contudo, ultrapassado o frenesi que toda novidade traz em si, a real idade se impõe, nua e crua, e a vida como ela é trata de afastar qualquer aparência do real.

17. A vida dos entregadores não melhorou, aliás piorou. A condição de MEI Microempresário Individual é uma precarização da relação de emprego, a formalização da informalidade, sem quaisquer benefícios ao trabalhador. Muito pelo contrário! $\mathrm{O}$ que de fato ocorreu no setor de entregas rápidas é a migração do emprego formal para o MEI.
\end{abstract}

Nessa Ação Civil Pública, o Ministério Público do Trabalho trouxe importante dado estatístico sobre a migração do trabalho com a carteira de trabalho anotada (regime CLT) para a modalidade de trabalho "autônomo", revelando que 56,3\% desses trabalhadores contavam com experiência prévia via CLT, não atuando anteriormente na qualidade de "autônomos", conforme trecho abaixo reproduzido:

\begin{abstract}
18. A pesquisa denominada Entregadores - Questões Socioeconômicas nos Serviços por Aplicativos da Fundação Instituto de Administração - FIA [fls.971/1.077], juntada à contestação, confirma que "os entregadores que atuam via operador logístico possuíram experiência profissional de entrega majoritariamente via CLT (56,3\%)" [ fl. 998 ], para, afinal, concluir que "na análise dos entrevistados que possuíam experiência anterior com a prestação de serviço de entregas, o vínculo estabelecido de trabalho predominante era o celetista $(53,40 \%)$, por meio de contrato na CLT" [fls. 984]
\end{abstract}

Decorre daí a constatação de que a sociedade da informação revela seu viés mais perverso, considerando que por trás desses aparatos digitais, da inteligência artificial ou dos algoritmos, o capital se esconde e se esquiva da observância dos preceitos fundamentais do trabalho, notadamente do trabalho digno.

Nesse sentido, a decisão liminar proferida em outra Ação Civil Pública (processo autuado sob o número 1000405-68.2020.5.02.0056, em trâmite perante a 56 Vara do Trabalho de São Paulo/SP) também movida pelo Ministério Público do Trabalho da Procuradoria Regional do Trabalho de São Paulo contra o Rappi, cujo objeto foi a concessão de garantias mínimas de saúde e segurança desses trabalhadores que não paralisaram suas atividades no momento da pandemia do coronavírus (COVID19), o Juiz Elizio Luiz Perez assim demostrou a preocupação com esses trabalhadores:

É direito dos trabalhadores, de forma ampla, a redução dos riscos inerentes ao trabalho, por meio de normas de saúde, higiene e segurança (CF 7o, caput e XXII). 
Parte da responsabilidade pela efetivação desse direito incumbe às empresas (Convenção no 155 da OIT, arts. 16/21; Decreto no 1254/94 da Presidência da República). A Lei no 8.080/90, invocada pelo autor, dispõe que a saúde é direito fundamental do ser humano, cujo pleno exercício deve ser promovido pelo Estado, sem exclusão da responsabilidade de todos, inclusive das empresas (art. 2o, caput e parágrafo 2o). Também a Lei 13.979/20, ao dispor sobre medidas para enfrentamento da emergência de saúde pública, incorpora as diretrizes do Regulamento Sanitário Internacional (art. 2o, parágrafo único; art. 3o, § 2o, III); este, em seu art. 18, "2", estabelece a possibilidade de implementação de tratamento, entre outros, de meios de transporte, mercadorias e encomendas, a fim de remover infecção ou contaminação. Ainda de forma ampla, a natureza das atividades da ré impõe responsabilidade objetiva sobre eventuais danos causados aos prestadores de serviços (CC 927).

Dessa maneira, a sociedade hodierna precisa trazer esses trabalhadores invisíveis para a luz, buscando mecanismos legais de proteção e tutela do direito desses trabalhadores, regulando essa nova modalidade de trabalho advindo do avanço tecnológico, retirando-os desse ambiente de cegueira social.

Há necessidade da criação de uma consciência global sobre a importância do desenvolvimento do pleno emprego decente e sustentável, utilizando os alicerces da Agenda 2030 (ONU, 2015), promovendo uma vida digna para esses trabalhadores vulneráveis, mediante a fixação de regras internacionais para direcionar todos os países na busca do trabalho decente, efetivando o Pacto Global do Emprego (OIT, 2009).

Aliada ao regramento internacional, existe a necessidade de um amplo debate na sociedade brasileira sobre o futuro do trabalho, reforçando o ideal de "democracia concertada" (CALDAS; TOMAZ, 2020, p. 53), assim como a necessidade identificada por Cuesta (2017, p. 130) no sentido de que "parece necessário reconfigurar os pilares do Estado de Bem-estar para garantir o cumprimento de seus objetivos originais."10.

\section{5 - CONCLUSÃO}

O mundo do trabalho atravessa um período de mudanças profundas alavancadas pela velocidade da social atual, pelas inovações tecnológicas e pela globalização, que colocam em questão em xeque a própria natureza e o futuro do trabalho, acendendo o alerta sobre a dignidade da pessoa humana e a busca do bem-estar social (bem comum).

\footnotetext{
10 Texto original: "parece necesario reconfigurar los pilares dei Estado dei Bienestar para garantizar e! cumplimiento de sus objetivos originales".
} 
O uso da tecnologia e da internet é um caminho sem volta. A sociedade futura cada vez mais estará interconectada, desenvolvendo e aprimorando as relações em ambiente virtual, ou ainda, substituindo os trabalhadores por máquinas, portanto, urge a necessidade de o Direito do Trabalho oferecer proteção a essa classe de trabalhadores que atuam, e continuarão atuando, nesse universo digital, assim como envidando esforços para garantir a continuidade do emprego.

Os trabalhadores invisíveis são colocados à margem da sociedade, fora da vitrine social, e suas atividades são colocadas pela coletividade como secundárias, sem pouca importância, não possuindo voz para brigarem pelos seus anseios e direitos de sua categoria profissional.

A flexibilização da legislação trabalhista não apenas enfraqueceu a luta desses trabalhadores, mas também os privou do acesso à Justiça, de modo que estão em verdadeira posição de submissão e altamente expostos ao poder do capital, a exemplo da redução salarial forçada que foram submetidos durante a pandemia do COVID-19, momento em que mais necessitavam de sua renda como fonte de sua subsistência.

Surge a necessidade de se buscar a construção de mecanismos legais de proteção desses trabalhadores invisíveis inseridos na sociedade da informação, pois estão em notória condição de vulnerabilidade frente ao mercado de trabalho imerso na tecnologia.

Defende-se nesse estudo a necessidade de o Estado buscar soluções econômicas e legislativas para oferecer não apenas novas oportunidades de trabalho, mas o desenvolvimento desses novos trabalhos mediante a concessão de tutela dos direitos básicos dos trabalhadores, através da efetividade da Agenda 2030 (ONU, 2015), da busca da implementação do Pacto Global do Emprego (OIT, 2009) e do exercício da democracia concertada.

\section{REFERÊNCIAS}

AGÊNCIA IBGE NOTÍCIAS - www.agenciadenoticias.ibge.gov.br - Disponível em: https://agenciadenoticias.ibge.gov.br/agencia-noticias/2012-agencia-denoticias/noticias/27821-desemprego-atinge-12-6-no-trimestre-ate-abril-com-queda-recordena-ocupacao - Acesso em: 15.06.2020.

BARRETO JUNIOR, Irineu Francisco; NASPOLINI, Samyra Haydêe Dall Farra. Proteção de informações no mundo virtual: a LGPD e a determinação de consentimento do titular para tratamento de dados pessoais in Cadernos Adenauer xx (2019), $n^{\circ} 3$, Proteção de 
dados pessoais: privacidade versus avanço tecnológico Rio de Janeiro: Fundação Konrad Adenauer, outubro 2019.

BAUMAN, Zygmunt. Globalização: as consequências humanas. Tradução Marcus Penchel. Rio de Janeiro: Jorge Zahar, 1999.

BBC NEWS BRASIL - $\underline{\text { www.bbc.com }}-$ Disponível em: https://www.bbc.com/portuguese/internacional-51983863 - Acesso em: 14.06.2020.

BECK, Ulrich. O que é globalização? Equívocos do globalismo: respostas à globalização. São Paulo: Paz e Terra, 1999.

BORGES, Ronaldo Divino; SILVA, Lawrenberg Advíncula da. Trabalhadores invisíveis: Um retrato social de Alto Araguaia. Trabalho submetido ao XXII Prêmio Expocom 2015, na Categoria Ensaio Fotográfico Artístico, modalidade Produção Transdisciplinar. Disponível em: http://www.portalintercom.org.br/anais/centrooeste2015/expocom/EX46-0004-1.pdf Acesso em 12.06.2020.

CALDAS, Roberto Correia da Silva Gomes; TOMAZ, Carlos Alberto Simões de. Efetividade dos direitos humanos e democracia: a soberania constitucional cooperativa entre a ordem estatal e a ordem internacional na sociedade do risco e da informação. Revista Opinião Jurídica, Fortaleza, v. 18, n, 29, p. 49-76, set./dez. 2020.

CASTELLS, Manuel. A sociedade em rede - A era da informação: economia, sociedade e cultura, v.01. São Paulo: Paz e Terra, 2019.

COSTA, Fernando Braga da. Moisés e Nilce: retratos biográficos de dois garis. Um estudo de psicologia social a partir de observação participante e entrevistas. Tese apresentada ao Instituto de Psicologia da Universidade de São Paulo como parte dos requisitos para obtenção do título de Doutor em Psicologia. São Paulo, 2008. Disponível em: https://www.teses.usp.br/teses/disponiveis/47/47134/tde-09012009-154159/pt-br.php

Acesso em 20.06.2020.

CUESTA. Henar Álvarez. El futuro del trabajo vs. el trabajo del futuro implicaciones laborales de la industria 4.0. Editoral Colex, 2017.

O ESTADO DE SÃO PAULO, ano 141, nº 46275, edição de domingo, 28.06.2020.

FRANCO, David Silva; FERRAZ, Deise Luiza da Silva. Uberização do trabalho e acumulação capitalista - Cadernos EMBAPE.BR, V. 17, Edição Especial - FGV - Rio de Janeiro - Disponível em: http://www.scielo.br/scielo.php?pid=S167939512019000700844\&script=sci_arttext\&tlng=pt - Acesso em: 20 abr.2020.

FULLER, Greice Patrícia; SOARES, Roger da Silva Moreira. A tutela penal dos dados empresariais na sociedade da informação. Revista Jurídica da Presidência, Brasília, v. 20, n.121, Jun/Set.2018, p. 408-438 https://revistajuridica.presidencia.gov.br/index.php/saj/article/view/1487 - Acesso em $\underline{15.06 .2020 .}$. 
GAIA, Fausto Siqueira. As novas formas de trabalho no mundo dos aplicativos: o caso “UBER". 2018. 360 f. Tese (Doutorado em Direito) - Programa de Estudos Pós-Graduados em Direito, Pontifícia Universidade Católica de São Paulo, São Paulo, 2018. Disponível em: https://tede2.pucsp.br/handle/handle/21889 - Acesso em: 14.06.2020.

GUIA TRABALHISTA - $\quad$ Disponível em: http://www.guiatrabalhista.com.br/tematicas/seguro_desemprego.htm - Acesso em: 11.06.2020.

INDÚSTRIA 4.0 - Disponível em: http://www.industria40.gov.br/ - Acesso em: 15.06.2020. LARA, Ricardo; SILVA, Mauri Antônio. Trabalho e crise social no Brasil contemporâneo. in: Riqueza e miséria do trabalho no Brasil IV: trabalho digital, autogestão e expropriação da vida/organizado por Ricardo Antunes - 1 ed. São Paulo: Boitempo, 2019.

INSTITUTO BRASILEIRO DE GEOGRAFIA E ESTATÍSTICA (IBGE) www.censo2010.ibge.gov.br - Disponível: https://censo2010.ibge.gov.br/noticiascenso.html?busca=1\&id=1\&idnoticia=2074\&t=desocupacao-fica-4-7-dezembro-fecha-2011media-6-0\&view=noticia - Acesso em: 15.06.2020.

MARTINS, Marcelo Guerra. Análise econômica do direito na sociedade da informação in. $O$ direito na sociedade da informação IV: movimentos sociais, tecnologia e a atuação do estado/coordenador Roberto Senise Lisboa. São Paulo: Almedina, 2020.

MENDES, Laura Zimmermann Ramayana. E-COMMERCE: origem, desenvolvimento e perspectivas. Trabalho de conclusão de graduação. Universidade Federal do Rio Grande do Sul. Disponível em: https://lume.ufrgs.br/handle/10183/78391 - Acesso em: 09.12.2020.

MOREIRA, Teresa Coelho. Algumas questões sobre o trabalho 4.0. Revista eletrônica [do] Tribunal Regional do Trabalho da $9^{a}$ Região, Curitiba, PR, v. 9, n. 86, p. 152-167, mar. 2020 - Disponível em: https://hdl.handle.net/20.500.12178/170751 - Acesso em: 16.06.2020.

NASPOLINI, Samyra Haydêe Dal Farra; FERREIRA, Luís Filipe Fernandes. Empresa e direitos humanos em uma economia globalizada. Revista de Direito Empresarial RDEmp, Belo Horizonte, ano 17, n. 1, p. 95 - 113, jan./abr. 2020.

ORGANIZACIÓN INTERNACIONAL DEL TRABAJO - www.ilo.org - Disponível em: https://www.ilo.org/jobspact/lang--es/index.htm - Acesso em 14.06.2020.

ORGANIZAÇÃO PAN-AMERICANA DA SAÚDE - OPAS BRASIL - www.paho.org Disponível em: https://www.paho.org/bra/index.php?option=com_content\&view=article\&id=5847:regulamen to-sanitario-internacional-rsi\&Itemid=812 - Acesso em: 13.06.2020.

PLATAFORMA AGENDA 2030 - www.agenda2030.com.br - Disponível em: http://www.agenda2030.com.br/ods/8/ - Acesso em: 11.06.2020 
PORTO, Marcos da Silva. Direito do Trabalho e desenvolvimento: crise e desafios do projeto constitucional. 2016. Dissertação (Mestrado em Desenvolvimento no Estado Democrático de Direito) - Faculdade de Direito de Ribeirão Preto, Universidade de São Paulo, Ribeirão Preto, 2016. doi:10.11606/D.107.2017.tde-01092017-085318. Acesso em: 28.09.2020.

RODRIGUES, Carlos Alexandre. A uberização das relações de trabalho. Revista dos Tribunais, vol. 996/2018, p. 311 - 341, Out/2018, DTR\2018\19928.

SILVEIRA, Everton Caldas; MEIRELES, Edilton. A autonomia privada na reforma trabalhista e a vedação ao retrocesso social. Revista de Direito do Trabalho, vol. 202/2019, p. 55 - 66, Jun/2019, DTR\2019\31931.

SOARES, José de Lima. Precarização e flexibilização do trabalho no contexto da reestruturação e descentralização produtiva na indústria de Catalão (GO) in: Riqueza e miséria do trabalho no Brasil IV: trabalho digital, autogestão e expropriação da vida/organizado por Ricardo Antunes - 1 ed. São Paulo: Boitempo, 2019.

SODRÉ, M. Antropológica do espelho. Petrópolis: Vozes, 2002.

TEIXEIRA, João Fernandes. O cérebro e o robô: inteligência artificial, biotecnologia e a nova ética. São Paulo: Paulus, 2015.

TEIXEIRAS, Carolina de Souza Novaes Gomes; BARCELOS, Débora de Jesus Rezende. A repercussão dos efeitos da crise no direito do trabalho: reforma trabalhista e a teoria da flexibilização como instrumento de controle da economia Revista de Direito do Trabalho, vol. 192/2018, p. 79 - 122, Ago/2018. DTR\2018\18229

THOMPSON, John B. A nova visibilidade. Revista MATRIZes N. 2 abril 2008.

TRIBUNAL SUPERIOR DO TRABALHO - www.tst.jus.br - Disponível em: http://www.tst.jus.br/noticias/-/asset_publisher/89Dk/content/id/24724445 - Acesso em: 12.06.2020.

TRIVINHO, Eugênio. Glocal: visibilidade mediática, imaginário bunker e existência em tempo real. São Paulo: Annablume, 2012.

A explosão do cibermundo: velocidade, comunicação e (trans)política na civilização tecnológica atual. Organizador Eugênio Trivinho. São Paulo: Annablume, 2017.

VIEGAS, Cláudia Mara de Almeida. Flexibilização das normas trabalhistas como ônus da crise econômica: o trabalhador pagará a conta? Revista de Direito do Trabalho, vol. 170/2016, p. 105 - 136, Jun/Jul. 2016, DTR\2016\20498

VIRILIO, Paul. Velocidade e política. Tradução Celso Mauro Paciornik. São Paulo: Estação Liberdade, 1996.

Revista de Direito, Governança e Novas Tecnologias | e-ISSN: 2526-0049 | Encontro Virtual | v. 6 | n. 2 | p. 01 - 21 | Jul/Dez. 2020. 